\title{
Navigating a research partnership between academia and industry to assess the impact of personalized genetic testing
}

\author{
Lisa Soleymani Lehmann, MD, PhD ${ }^{1,2}$, David J. Kaufman, $\mathrm{PhD}^{3}$, Richard R. Sharp, PhD ${ }^{4}$ \\ Tanya A. Moreno, $\mathrm{PhD}^{5}$, Joanna L. Mountain, $\mathrm{PhD}^{6}$, J. Scott Roberts, $\mathrm{PhD}^{7}$ \\ and Robert C. Green, MD, $\mathrm{MPH}^{8}$
}

\begin{abstract}
Purpose: To describe the process of structuring a partnership between academic researchers and two personalized genetic testing companies that would manage conflicts of interest while allowing researchers to study the impact of this nascent industry.

Methods: We developed a transparent process of ongoing communication about the interests of all research partners to address challenges in establishing study goals, survey development, data collection, analysis, and manuscript preparation. Using the existing literature on conflicts of interest and our experience, we created a checklist for academic and industry researchers seeking to structure research partnerships.
\end{abstract}

Results: Our checklist includes questions about the risk to research participants, sponsorship of the study, control of data analysis, freedom to publish results, the impact of the research on industry

\section{INTRODUCTION}

In recent years, there has been a growth in the number of companies that offer personalized genetic testing either directly to consumers or upon referral from a health-care provider. $^{1}$ Services offered by these companies include provision of data on ancestry, carrier status for recessive mutations, personalized responses to medications, and information on genetic predispositions to complex diseases such as diabetes, heart disease, and cancer. These companies provide genetic information that proponents contend may motivate or enable consumers to improve health-related behaviors $^{2-4}$ and there are some data to suggest that the ability of individuals to directly access personal genetic information can be empowering. ${ }^{5,6}$

The growth of these companies has raised a number of concerns..$^{7-10}$ A primary concern is that customers who obtain this information might make clinical or behavioral decisions based on their personal genetic information without consulting a physician and that some of these decisions could be harmful. ${ }^{11} \mathrm{~A}$ related concern is that some of the disease risks customers, openness to input from all partners, sharing results before publication, and publication of industry-specific data. Transparency is critical to building trust between partners. Involving all partners in the research development enhanced the quality of our research and provided an opportunity to manage conflicts early in the research process.

Conclusion: Navigating relationships between academia and industry is complex and requires strategies that are transparent and responsive to the concerns of all. Employing a checklist of questions prior to beginning a research partnership may help to manage conflicts of interest.

Genet Med 2012:14(2):268-273

Key Words: conflicts of interest; direct-to-consumer; partnership; personalized genetic testing; personalized medicine

presented are based on genotype-phenotype associations that are yet to be confirmed in some ethnicities or shown to have clear clinical utility. ${ }^{12,13}$ As this information is provided outside of a traditional medical setting, it is also possible that individuals may misinterpret the significance of the findings and decline medically recommended tests. ${ }^{14}$ Some worry that as a result of potential misunderstandings, consumers may inappropriately use health-care resources ${ }^{15}$ by asking for unnecessary genetic testing or early detection procedures. ${ }^{16}$ There are also concerns that some consumers may have a negative psychological reaction to genetic information. ${ }^{17}$

The Center for Devices and Radiological Health of the US Food and Drug Administration has recently challenged the ability of personal genetic testing companies to provide meaningful interpretations of genetic data directly to consumers. ${ }^{18-20}$ Although the future regulation of the personalized genetic testing industry remains uncertain, there is little doubt that companies will continue to proliferate as the technology to both generate and interpret genetic information is rapidly advancing.

The last two authors contributed equally to this work

${ }^{1}$ Department of Medicine and Center for Bioethics, Brigham and Women's Hospital, Boston, Massachusetts, USA; ${ }^{2}$ Department of Global Health and Social Medicine, Harvard Medical School, Boston, Massachusetts, USA; ${ }^{3}$ Genetics and Public Policy Center, Johns Hopkins University, Washington, DC, USA; ${ }^{4}$ Department of Bioethics and Genomic Medicine Institute, Lerner College of Medicine, Cleveland Clinic and Center for Genetic Research Ethics and Law, Case Western Reserve University, Cleveland, Ohio, USA; ${ }^{5}$ Pathway Genomics, San Diego, California, USA; ${ }^{6} 23$ andMe, Mountain View, California, USA; ${ }^{7}$ Department of Health Behavior and Health Education, University of Michigan School of Public Health, Ann Arbor, Michigan, USA; ${ }^{8}$ Department of Medicine, Division of Genetics, Brigham and Women's Hospital, Harvard Medical School, and Partners Center for Personalized Genetic Medicine, Boston, Massachusetts, USA. Correspondence: Lisa Soleymani Lehmann (LLehmann1@partners.org) 
Despite these regulatory uncertainties and potential concerns, the impact of these new test products on health and behavior is largely unexplored. What are the harms and benefits of obtaining personal genetic information? What motivates an interest in personalized genetics? Do customers correctly interpret the results they are given? Do customers use this information to make medical decisions? Does the information motivate customers to make changes in their health behaviors? With whom do customers share their personal genetic information? To address these gaps in knowledge and inform future policy, several retrospective studies and one small randomized trial have been conducted to survey consumers about their motivations for and responses to personal genome services. ${ }^{21-24}$ Several of these studies have involved partnerships between academic investigators and personalized genetic testing companies.

Such partnerships present novel research opportunities but raise concerns for both academicians and industry representatives. A primary concern of academicians is the ability to ensure the objectivity of the research when partnering with a company that has a financial interest in research outcomes. ${ }^{25,26}$ Developing a partnership with industry, in which company representatives are intimately involved in the research, may give the appearance of compromised academic objectivity and thus undermine public and professional acceptance of the research. ${ }^{27}$ On the other hand, a primary concern of company representatives is the potential for poor quality or biased research that inappropriately threatens their reputation or diminishes the perceived value of their product. Additional concerns center on the amount of time and effort required of company representatives to participate in academic partnerships and the potential impact of study participation on a company's relationships with its customers.

These considerations suggest that collaborations between academic researchers and personal genomic testing companies should be approached by both sides with transparency about the risks and benefits of working together. In this report, we describe our experiences structuring a research partnership involving academicians and two personalized genetic testing companies at the start of a new project in which we are prospectively studying the impact of personalized genetic testing. We believe such partnerships are essential for understanding the impact of this new industry and present a framework for developing research collaborations that are sensitive to the needs of both industry and academic partners.

\section{The need for data on the impact of personalized genetic testing}

As noted above, there are a growing number of companies offering personalized genetic testing. To date, empirical studies on the impact of these services have not documented any harms of personal genetic testing. ${ }^{5,21,24}$ However, to better understand the potential benefits and risks that come with such information, prospectively designed research must be implemented to rigorously assess benefits and harms.

To generate such data, we established a collaboration between academic researchers and two companies that provide personalized genetic testing products: 23andMe and Pathway Genomics. The resulting collaboration will allow us to perform the first prospective (before and after) survey of psychological and behavioral responses to personal genomics services. This study was initiated by academic researchers and is funded by the National Human Genome Research Institute. Two companies were initially involved in the development of this research. As the commercial landscape evolved, one company decided not to participate. As the funding for the project started, a different company was approached and agreed to participate, resulting in participation by two companies as originally proposed.

\section{Challenges in the research development phase}

Creating a partnership required that we address the dual priorities of maintaining scientific rigor and objectivity while respecting the concerns of the industry being studied. Academic investigators and industry scientists had to develop solutions that would satisfy both partners. In establishing this partnership, we discussed several potential challenges, outlined below, that we thought might arise during the course of establishing study goals, survey development, data collection, analysis, and manuscript preparation. There were no significant disagreements between industry and academic partners. Differences of perspective on issues did not necessarily align with academic or industry affiliation. That is, it was not the case that all industry or all academic partners were always on the same side of an issue that was being considered. Because we developed a collaborative approach from the outset, our conversations were always cordial and constructive. Of note, we did not develop any legal agreements or contracts such as nondisclosure agreements.

Establishing study goals. Our collaboration began well in advance of the study. Representatives from two companies were involved in defining the study aims prior to application for research funding. For example, company scientists encouraged broadening the focus of the project from direct-to-consumer testing to the use of personalized genetic information made accessible to individuals, regardless of how they receive this information.

During the development of the grant application, the shared interest in evaluating customers' understanding of their genetic risk information required development of a plan to protect customers' privacy while allowing access to individual genetic risk information. Company scientists were interested in pursuing this goal and worked with academic colleagues to develop a process that satisfied both partners. In this instance, a third-party small business specializing in Web survey design was chosen to implement the study survey. This company has significant experience in protecting sensitive health information and will be able to provide the research team with a deidentified data set upon project completion. Companies also provided letters of support for the grant proposal to the National Institutes of Health, and regular communication was established between scientists from each company and academic study leaders. 
Survey development. Industry representatives participated fully in development and review of the survey instrument before it was administered to their customers. Research scientists from each company joined academic researchers in a two-day, studywide retreat to refine study objectives and develop the survey questions. Among the issues that we discussed for which there were differences of opinion were the tradeoff between using validated scales versus concerns about the positive and negative framing of questions within existing instruments and the length of the surveys. One company had extensive experience with survey development and its application in the context of personal genomic testing. The expertise of this company's survey specialist was instrumental in the development of the survey. Another company asked genetic counselors to review survey questions based on their experiences with customers. Company representatives' knowledge of their customer base allowed them to suggest survey items assessing responses that had not been considered by others. For example, 23andMe shared that many of their customers choose personalized genetic testing to obtain information not about their health but about their genealogy. This information allowed us to frame and develop our survey in a way that was clearer and more relevant to the customers who were responding.

Data analysis. Questions about data analysis and sharing were largely negotiated in advance of the study. Academic researchers initially wanted to compare reactions to different presentations of genetic data by comparing responses of the two companies' customers. One notable difference between the companies relates to their approach to genetic counseling. Pathway Genomics has on-site genetic counselors who are available, by telephone, to customers before and after genetic testing. There is no additional fee for this service. 23andMe refers customers to a nationwide network of board-certified genetic counselors to offer independent genetic counseling services. These services occur by telephone for an additional fee, but the service is described as a covered benefit for most individuals with commercial health insurance.

Comparing the two customer groups would allow assessment of the relationship between counseling models and responses to testing. Understandably, the company partners did not want to participate in research resulting in direct comparisons of testing products as they were sensitive to the possibility that real or perceived marketplace advantages might result from these comparisons. Based on these considerations and the fact that this question was not the primary research question of our study, the research team agreed that analyses and publications would not directly compare one company to another.

Although it was agreed that academic researchers would have primary responsibility for data analysis, the research team decided that company-specific data would not be made public or shared with other companies. Rather, we agreed that each company would receive their own individual customers' survey data. Companies will therefore have rights to their own raw data and can independently pursue data analysis on their customers' responses. Although the companies will not be directly involved in most aspects of primary data analysis, they will still have input into the analysis and can request additional analysis of variables that may be of interest. Decisions to proceed with additional analysis requested by either academic or industry scientists will be based on the scientific merit of the request and decided by the co-principal investigators of the study, with input both from academic and industry coinvestigators.

Human subject concerns. Industry concerns about customer privacy and confidentiality also guided our study design. The academic members of the partnership were asked to consider the possible unintended impact the study might have on the ongoing relationships between the companies and their customers.

To prevent academic researchers from gaining direct access to customers' private information, the companies agreed to send e-mail links to customers, allowing the third-party survey firm to communicate with those who elect to respond. The survey firm will assign each participant a unique study ID number that will be sent to the academic investigators with the corresponding genetic reports. As the customers' genetic information will be sent directly to the researchers, not the survey firm, all information about customers' genetic risk information will be deidentified.

The unique ID will be used to identify participants' survey responses. Academic investigators will not have access to personal information such as names or e-mail addresses. Customers who agree to participate in the study will be asked to share their contact information with the survey firm, which will contact them directly regarding study participation.

It should be noted that companies will not select customers for participation in this study. Rather, all customers will be sent a link that they can use to opt in to the study. This method of enrolling customers should reduce the perception of bias associated with company involvement in this study. Company concerns about unnecessarily burdening customers also led to discussions about the optimal length of surveys. The investigators together agreed that surveys should not exceed $30 \mathrm{~min}$ in length and that the number of e-mail reminders that will be sent to customers should be limited.

The study is currently under review by the academic institutional review board and the institutional review board submission was reviewed by both academic and industry scientists prior to submission.

Publication. Authorship of papers reporting study findings was another issue discussed in advance of our research collaboration. Both academic investigators and industry researchers want to see research findings presented in an unbiased manner that neither overstates the benefits of personalized genetic testing nor underestimates its risks. Members of the research team discussed the possibility that study results might be viewed as biased due to industry involvement. Company scientists were also concerned about the amount of time that they might be 
asked to spend in coauthoring research publications as this is not their primary focus. At the start of the study, company representatives agreed that data may be published by the investigative team free from any editorial control by either company. Company scientists will be invited to be coauthors on publications, subject to the extent that they have time available to participate. Authorship from both academic investigators and industry researchers will also be assigned in accordance with established authorship criteria developed by major medical journals. ${ }^{28,29}$

\section{A framework for collaboration}

Research studies that seek to understand the impact of personal genetic information will benefit from rigorous analysis of the impact of these services on consumers. Partnering with companies that provide academic researchers with access to their customers is the most effective way to examine these questions. Academic investigators are therefore faced with the choice of not doing this research at all or finding ways to structure these collaborations in ways that do not compromise the objectivity of the research. Based on our experience, we believe it is possible to structure these collaborations in a way that does not compromise the objectivity of the research and that is sensitive to the concerns and interests of all.

Those who have analyzed academic-industry partnerships argue that direct research involvement by companies whose product is being studied carries a risk of overstating product benefits and underestimating risks. ${ }^{30-33}$ The results of biased research could harm patients and erode societal trust in the medical research enterprise. We are aware of these concerns and, both as researchers and industry representatives, have held them as guiding principles as we negotiated this partnership. Having carefully examined key assumptions about our partnership in advance of the research study, we believe that valuable and objective information will be obtained.

The existence of a conflict of interest does not mean that bias will occur, but it does increase the risk of compromising primary research interests by secondary interests. ${ }^{34}$ This risk is present in both partners in that academic researchers have conflicts of interest stemming from their desire for academic success or their own preconceived ideas about the value or lack of value of personal genomics services. In this case, academic researchers' prior beliefs about the potential benefits or harms of personalized genetic testing could influence choices about research design (e.g., imbalanced focus in survey questions on negative outcomes of testing) or bias results in much the same way that a company's financial conflict of interest could influence study interpretations. ${ }^{35}$

Equally important, the existence of a conflict of interest does not mean that the industry scientist or academic researcher has intentions that are at odds with the goals of the research. What it does mean is that a clearly specified and transparent framework for minimizing the introduction of bias should be developed and adhered to throughout the study. To this end, it is critical to provide an a priori framework for identifying, analyzing, and managing unforeseen issues as they emerge over the course of a study.

This framework entails clarity about study objectives, multiple academic and industry partners, transparent communication between partners, acknowledgment of the interests of partners, resolution of potential concerns as early as possible in the research process, and disclosure of competing interests.

Although disclosure of conflicts is a necessary step in this process, the introduction of bias or perceptions that may undermine the public trust in research may occur if conflicts are not eliminated or managed. The Institute of Medicine has called for a general rule that researchers should not conduct research involving human subjects if they have a significant financial interest in the outcome of the research. The Institute recommends that exceptions to this policy be publicly disclosed and permitted only when an individual's participation is essential for the conduct of the research and where the researchers establish effective mechanisms for managing the conflict and protecting the integrity of the research. ${ }^{27}$

There are multiple ways in which investigators can manage conflicts of interest. These include public disclosure of the conflict, monitoring of the research by independent reviewers, divestiture of an investigator's conflicting financial interests, severance of an investigator's relationships that create the conflict, or disqualification of an investigator from participation in part of the research. ${ }^{36}$ Disqualifying investigators who have a conflict is an extreme solution that is effective, but it is likely to diminish creative collaborations that can benefit society. We recommend a more nuanced and thoughtful approach to managing conflicts of interests that cannot be avoided.

To mitigate conflicts, we suggest that academic researchers and company scientists raise several key questions that help to elucidate sources of conflict (Table 1). In addition, all partners should ask if there is sufficient transparency about the interests of those involved. The potential for conflicts for both academic and industry representatives should be acknowledged and discussed. A process for negotiating unforeseen differences or issues that arise as the study progresses should also be laid out ahead of time. Our process for managing potential conflicts of interest involved transparent conversation about the questions outlined in Table 1. These questions provide a framework for a shared understanding of competing interests and the ability to proactively address concerns that may introduce bias into the study. Through explicit disclosure of conflicts, reflection on the potential implications of these conflicts, a research design involving multiple academic and industry partners to ensure that the biases of any one investigator are less likely to influence final results, along with clear and regular communication about the interests of all partners, we have tried to ensure that bias would not be introduced into the design, conduct, or dissemination of our research.

The preeminent concern for all research partners should be the protection of the rights and welfare of research participants. Awareness of this overarching concern helps to provide 


\begin{tabular}{|c|c|}
\hline $\begin{array}{l}\text { Questions for academic } \\
\text { researchers }\end{array}$ & Questions for industry researchers \\
\hline \multirow{2}{*}{$\begin{array}{l}\text { Will the partnership } \\
\text { result in increased risk to } \\
\text { research participants? }\end{array}$} & $\begin{array}{l}\text { Will the research produce new knowledge } \\
\text { that is relevant to the company? }\end{array}$ \\
\hline & Are multiple academic partners involved? \\
\hline $\begin{array}{l}\text { Is the research sponsor } \\
\text { independent of the } \\
\text { industry that is being } \\
\text { studied? }\end{array}$ & $\begin{array}{l}\text { Are the academic partners committed } \\
\text { to conducting high-quality objective } \\
\text { research? }\end{array}$ \\
\hline $\begin{array}{l}\text { Are any academic } \\
\text { investigators paid } \\
\text { consultants for the } \\
\text { company? }\end{array}$ & $\begin{array}{l}\text { Do the academic partners have concern } \\
\text { for the impact of the research process on } \\
\text { customers, including customer privacy and } \\
\text { information security? }\end{array}$ \\
\hline $\begin{array}{l}\text { Are multiple industry } \\
\text { partners involved? }\end{array}$ & $\begin{array}{l}\text { Are the academic partners open to input } \\
\text { from the company? }\end{array}$ \\
\hline $\begin{array}{l}\text { Who controls the analysis } \\
\text { of data? }\end{array}$ & $\begin{array}{l}\text { Will the company be informed of the } \\
\text { results prior to publication? }\end{array}$ \\
\hline $\begin{array}{l}\text { Is there freedom to } \\
\text { publish all results? }\end{array}$ & Will company-specific data be published? \\
\hline $\begin{array}{l}\text { Is there transparency } \\
\text { about the interests of all } \\
\text { partners? }\end{array}$ & $\begin{array}{l}\text { Is there transparency about the interests of } \\
\text { all partners? }\end{array}$ \\
\hline
\end{tabular}

an important perspective on areas of conflict and allow for a balance of the research interests with each stakeholder's interest. For example, industry concerns about participant confidentiality and study burden guided our decisions about how participants would be contacted, what information researchers could access, and how nonresponders would be recontacted.

The objectivity of the research is enhanced by a funder with no financial or other interest in the companies being studied. In our case, the research was funded by the National Institutes of Health. In addition, control over the data analysis and the freedom to publish aggregate research results that could be viewed as favorable or unfavorable to the companies is essential to maintaining research integrity. Such control helps to ensure that the risks and benefits are not overstated. We therefore agreed in advance that the academic researchers will direct data analysis and publication, with no limitations on the results that can be published, except the agreement not to publish results from only one company or publish direct comparisons between the companies.

Navigating a partnership between personal genomic testing companies and academic researchers is a complex and dynamic process. Changing company needs and capacities may influence their ability and willingness to participate in such research. Despite the challenges of these relationships, developing robust constructive collaborations with companies is necessary if we are to understand the impact of this nascent industry on society and health care. Understanding each stakeholder's interests and the conflicts of interests in advance of the study is critical to managing these concerns.

\section{ACKNOWLEDGMENT}

This work was funded by National Human Genome Research Institute grants HG005092, HG004865, HG02213, HG003390, AG027841, and NIH 14L1RR025758-01.

\section{DISCLOSURE}

J. L. M. is employed by 23andMe. T. A. M. is employed by Pathway Genomics. The other authors declare no conflict of interest.

\section{REFERENCES}

1. Direct-to-Consumer Genetic Testing Companies. http://www.dnapolicy. org/resources/DTCTableAug2011Alphabydisease.pdf. Accessed 16 October 2011

2. Helgason A, Stefánsson K. The past, present, and future of direct-toconsumer genetic tests. Dialogues Clin Neurosci 2010;12:61-68.

3. Foster MW, Sharp RR. The contractual genome: how direct-to-consumer genomic services may help patients take ownership of their DNA. Person Med 2008;5:399-404.

4. McBride CM, Koehly LM, Sanderson SC, Kaphingst KA. The behavioral response to personalized genetic information: will genetic risk profiles motivate individuals and families to choose more healthful behaviors? Annu Rev Public Health 2010;31:89-103.

5. Bloss CS, Ornowski L, Silver E, et al. Consumer perceptions of directto-consumer personalized genomic risk assessments. Genet Med 2010;12:556-566.

6. McBride CM, Wade $\mathrm{CH}$, Kaphingst KA. Consumers' views of directto-consumer genetic information. Annu Rev Genomics Hum Genet 2010;11:427-446.

7. Frueh FW, Greely HT, Green RC, Hogarth S, Siegel S. The future of direct-toconsumer clinical genetic tests. Nat Rev Genet 2011;12:511-515.

8. Evans JP, Green RC. Direct to consumer genetic testing: avoiding a culture war. Genet Med 2009;11:568-569.

9. American College of Medical Genetics. Statement on direct-toconsumer genetic testing, 2007. http://www.acmg.net/AM/ Template.cfm? Section=Home3\&Template=/CM/ContentDisplay cfm\&ContentID=2395. Accessed 2 July 2011.

10. Kueh BM. Risks and benefits of direct-to-consumer genetic testing remain unclear. JAMA 2008;300:1503-1505.

11. Howard HC, Borry P. Personal genome testing: do you know what you are buying? Am J Bioeth 2009;9:11-13.

12. Janssens $A C$, van Duijn CM. An epidemiological perspective on the future of direct-to-consumer personal genome testing. Investig Genet 2010;1:10.

13. Grosse SD, Khoury MJ. What is the clinical utility of genetic testing? Genet Med 2006:8:448-450.

14. Eng C, Sharp RR. Bioethical and clinical dilemmas of direct-to-consumer personal genomic testing: the problem of misattributed equivalence. Sci Trans/ Med 2010;2:17cm5.

15. McGuire AL, Burke W. An unwelcome side effect of direct-to-consumer personal genome testing: raiding the medical commons. JAMA 2008;300:2669-2671.

16. Caulfield T. Direct-to-consumer genetics and health policy: a worst-case scenario? Am J Bioeth 2009;9:48-50.

17. Broadstock M, Michie S, Marteau T. Psychological consequences of predictive genetic testing: a systematic review. Eur J Hum Genet 2000;8:731-738.

18. Brower V. FDA to regulate direct-to-consumer genetic tests. J Nat/ Cancer Inst 2010;102:1610-2, 1617

19. Federal Register, Oversight of Laboratory Developed Tests; Public Meeting; Request for Comments, 2010. http://edocket.access.gpo.gov/2010/201014654.htm. Accessed 2 July 2011

20. FDA Executive Summary. Molecular and Clinical Genetics Panel. 8-9 March 2011. http://www.fda.gov/downloads/Advisory Committees/CommitteesMeetingMaterials/MedicalDevices/ MedicalDevicesAdvisoryCommittee/MolecularandClinicalGeneticsPanel/ UCM245660.pdf. Accessed 2 July 2011.

21. Kaufman D, Murphy BJ, Devaney S, Scott J. Direct From Consumers: A Survey of 1,048 Customers of Three Direct-to-Consumer Personal Genomic Testing Companies About Motivations, Attitudes, and Responses 
to Testing. Abstract 390. Annual Meeting, The American Society of Human Genetics, Washington, DC, 2-6 November 2010.

22. Bloss CS, Schork NJ, Topol EJ. Effect of direct-to-consumer genomewide profiling to assess disease risk. N Eng/ J Med 2011:364:524-534.

23. McGuire AL, Diaz CM, Wang T, Hilsenbeck SG. Social networkers' attitudes toward direct-to-consumer personal genome testing. Am J Bioeth 2009;9: $3-10$.

24. James KM, Cowl CT, Tilburt JC, et al. Impact of direct-to-consumer predictive genomic testing on risk perception and worry among patients receiving routine care in a preventive health clinic. Mayo Clin Proc 2011;86:933-940.

25. American Association of Medical Colleges. Protecting Patients, Preserving Integrity, Advancing Health: Accelerating the Implementation of COI Policies in Human Subjects Research. A Report of the AAMC-AAU Advisory Committee on Financial Conflicts of Interest in Human Subjects Research. Washington, DC: American Association of Medical Colleges, 2008.

26. DeAngelis CD, Fontanarosa PB. Impugning the integrity of medical science: the adverse effects of industry influence. JAMA 2008;299: 1833-1835.

27. Lo B, Fields MJ (eds). Committee on Conflict of Interest in Medical Research, Education, and Practice. Conflict of Interest in Medical Research, Education, and Practice. National Academies Press: Washington DC, 2009.
28. Davidoff F, DeAngelis CD, Drazen JM, et al.; International Committee of Medical Journal Editors. Sponsorship, authorship and accountability. CMAJ 2001; 165:786-788.

29. Bates T, Anic A, Marusic M, Marusic A. Authorship criteria and disclosure of contributions: comparison of 3 general medical journals with different author contribution forms. JAMA 2004; 292:86-88.

30. Institute of Medicine of the National Academies: Conflict of interest in medical research, education and practice, 2009. http://www.iom.edu/ CMS/3740/47464/65721.aspx. Accessed 20 June 2011.

31. Bekelman JE, Li Y, Gross CP. Scope and impact of financial conflicts of interest in biomedical research: a systematic review. JAMA 2003;289: 454-465.

32. Blumenthal D. Growing pains for new academic/industry relationships. Health Aff (Millwood) 1994;13:176-193.

33. Angell M. Is academic medicine for sale? N Engl J Med 2000;342: 1516-1518.

34. Thompson DF. Understanding financial conflicts of interest. N Engl J Med 1993:329:573-576.

35. Yarborough M, Sharp RR. Bioethics consultation and patient advocacy organizations: expanding the dialogue about professional conflicts of interest. Camb Q Healthc Ethics 2007; 16:74-81.

36 Parks MR, Disis ML. Conflicts of interest in translational research. J Transl Med 2004;2:1-4. 